\title{
Una unidad didáctica centrada en la comprensión de la percepción
} de la luz y la visión

\section{A teaching unit focused on understanding the perception of light and vision}

Por: Alejandro Pujalte, Paula Santamaria, Agustín Adúriz-Bravo y Elsa Meinardi ${ }^{1}$

\section{Resumen}

En nuestra experiencia como docentes hemos detectado que los fenómenos relacionados con la luz y la visión son de difícil comprensión para las y los estudiantes de cualquier nivel educativo.

Con el fin de que los alumnos/as puedan responder adecuadamente a la pregunta acerca de cómo vemos, desde un modelo de la luz como rayo, que permita relacionarla con los objetos y el ojo del observador, formulamos una propuesta innovadora de enseñanza que ensayamos con alumnos/as de 12 años (primer año de la Educación Secundaria Básica, en Argentina).

La unidad didáctica tiene como objetivo que las y los estudiantes puedan construir explicaciones progresivamente más potentes acerca de los fenómenos que involucran la percepción de la luz y la visión. Para ello, formulamos actividades que buscan dar cuenta de las concepciones alternativas que los alumnos/as poseen al respecto, muchas de las cuales se constituyen en obstáculos a la hora de aproximarse a los modelos científicos. De allí que la secuencia propuesta está centrada en la identificación y la superación de dichos obstáculos, de manera que las y los estudiantes logren considerar inadecuadas las muy frecuentes concepciones acerca de que vemos porque "algo" procede del ojo y que los objetos iluminados emiten luz, en vez de reflejarla. La puesta en práctica de esta unidad didáctica promovió la elicitación de las ideas alternativas de los alumnos/as, en tanto que las actividades desarrolladas permitieron ponerlas en discusión, desestabilizarlas y lograr que los modelos científicos presentados cobraran plausibilidad y potencia explicativa, lo que se evidenció a través de la reformulación de las formas argumentativas usadas para dar cuenta de los fenómenos.

${ }^{1}$ Grupo de Didáctica de la Biología, Centro de Formación e Investigación en Enseñanza de las Ciencias, Facultad de Ciencias Exactas y Naturales, Universidad de Buenos Aires, Argentina. E-mail: emeinardi@fibertel.com.ar 


\begin{abstract}
In our experience like teachers we have detected that the phenomena related to the light and the vision are of difficult understanding for the students, as much of primary level as secondary. In order that the students can suitably respond to the question about how we see, from a representational model of the light like ray, that allows to relate the light, the object and the eye of the observer, we formulated an innovating proposal of education that we tried with students of 12 years (first year of Basic Secondary Education, in the province of Bs. As.). The didactic unit has like objective that the students can construct explanations progressively more powerful throughout their development. For it, we formulated activities that look take into account the alternative conceptions that the students have on the matter, many of which constituted obstacles at the time of taking control of scientifically right models. From which the propose sequence is centered in the identification and the overcoming of these obstacles, so that the students can consider inadequate the very frequent conceptions of which we see because "something" comes from the eye and that the illuminated objects emit light, instead of reflect it. The implementation of this teaching unit promoted the elicitation of these misconceptions in students, while the activities allowed them in discussion, destabilize them and make presentations to scientific models plausibility and explanatory power as evidenced by the reformulation of the forms arguments used by students when explaining the phenomena.
\end{abstract}

\title{
Contexto de la experiencia
}

La propuesta que presentamos fue planificada atendiendo a los marcos teóricos investigados en la didáctica de las ciencias naturales y en la formación de profesores (Meinardi, 2007; Meinardi y col., 2010) y llevada adelante en un curso de 33 alumnos/as de 12 a 14 años.

Los contenidos conceptuales escogidos para la Unidad Didáctica fueron:

- La luz como entidad independiente de las fuentes y del ojo

- Fuentes de luz: primarias y secundarias

- Los elementos constituyentes de la visión

- Visión directa e indirecta

- Los modelos y las representaciones en ciencias como propuestas descriptivas y explicativas de carácter provisional.

Al mismo tiempo, mediante las actividades propuestas se intentó fomentar el trabajo cognitivo en los y las estudiantes mediante procesos tales como comparar, analizar, identificar e interpretar información, generar hipótesis, inferir, predecir, transferir, describir, explicar, argumentar, ejemplificar y debatir. En cada actividad se señalan algunos de los procesos más relevantes que se espera favorecer. 


\section{Objetivos}

El objetivo general de la Unidad Didáctica fue que los alumnos y alumnas puedan responder a la pregunta: ¿Cómo vemos? apelando a un modelo de la luz como rayo, que permita relacionar la luz, el objeto observado y el ojo del observador.

En cuanto al alcance de este objetivo general, en principio, asumimos que nuestros estudiantes se acercarían a construir modelizaciones de carácter bastante más descriptivo que explicativo (en tanto el nivel de profundidad que pueden alcanzar, dada la complejidad propia del tema y de la edad de los alumnos). La posibilidad de representar la luz como flecha -que a su vez "modelizaría" el rayo luminoso- apunta más bien al fenómeno de traslación direccional de la luz en su faceta más descriptiva. Sin embargo, en el transcurso de la aplicación de esta unidad se llegaron a producir aproximaciones con un grado interesante de potencia explicativa.

\section{Los objetivos específicos fueron que las alumnas y alumnos comprendan que:}

- La concepción de que "se puede ver porque salen rayos de los ojos" es inadecuada desde el punto de vista científico,

- Los objetos son visibles ya sea porque son fuentes primarias de luz o bien porque la reflejan

- No es posible ver la trayectoria del rayo de luz sin que éste se refleje en partículas materiales.

Consideramos pertinente exponer en primer término la unidad didáctica tal como fue concebida. En segundo lugar, se mostrarán algunos de los resultados alcanzados en su implementación práctica, en función de su relevancia para el análisis final, esto es, cuáles eran las concepciones de los alumnos/as al iniciarse la unidad y cómo pudieron evidenciarse indicios de cambio representacional a partir de actividades finales de evaluación.

\section{Desarrollo de la Unidad Didáctica}

A continuación presentamos las actividades desarrolladas. Al final de cada actividad, en cursiva, se expone una reflexión didáctica.

(Aclaración: En español, el género masculino en singular y plural incluye ambos géneros. Esta forma propia de la lengua oculta la mención de lo femenino. Pero, como el uso explícito de ambos géneros dificulta la lectura, para la unidad didáctica emplearemos el masculino inclusor en todos los casos)

\section{Clase I. Indagación de las ideas de los estudiantes}

\section{Actividad 1. ¿Sin darnos cuenta?}

El comienzo de la clase encuentra al docente acondicionando los elementos para la proyección de un video, para lo cual pide la colaboración de algunos alumnos. En esa instancia de preparación se juega a propósito (pero sin explicitarlo) con la ubicación de la 
pantalla y la dirección del proyector en relación con la formación de las imágenes, haciendo el docente el rol de que no sabe mucho del tema. Al mismo tiempo, enuncia a la clase las siguientes inquietudes:

-“¿Se puede observar la imagen si no está la pantalla o el proyector apunta hacia la apertura de la ventana?

-¿Debo acercar o alejar la pantalla? ¿Es lo mismo que modificar el foco?"

La actividad no se presenta formalmente como una indagación de ideas previas, pero sin dudas lo es. Carece de una estructura rígida preestablecida: el mismo juego de preparación de la actividad siguiente puede derivar en intervenciones docentes en función de la participación de los alumnos. Se enfrentan a la resolución de un problema real, ante la supuesta impericia del docente para lograr su propósito de adecuar el dispositivo proyector / pantalla. De allí que se logre significatividad a la hora de conseguir respuestas de los alumnos. En este sentido, tienen la posibilidad de identificar los elementos necesarios para la producción de imágenes nítidas, comparar distintas posibilidades en el logro de imágenes y predecir qué pasaría en determinadas circunstancias.

\section{Actividad 2. ¿Por qué puede ser importante la visión para el ser humano y para el resto de los animales?}

Antes de comenzar efectivamente con la proyección de un video, se plantea en forma oral la pregunta del acápite. El registro de las respuestas es efectuado por el docente en el pizarrón en la medida que vayan siendo planteadas (a la manera de "torbellino de ideas"). Algunas posibles respuestas:

Para: ver, diferenciar los colores, no chocarse contra las cosas cuando uno camina, ver televisión, jugar a los jueguitos, leer, reconocer cosas, los animales para poder cazar presas.

Esta es una típica actividad de indagación de ideas previas, en base a la modalidad "torbellino de ideas". Además de conocer las concepciones previas que traen los alumnos respecto de la visión, es interesante poder utilizar las respuestas como primer escalón en la construcción de explicaciones de nivel creciente de profundización y complejidad. Es muy probable que las explicaciones que formulen los alumnos en esta instancia revelen tautologías, como se puede evidenciar en las respuestas anotadas más arriba.

\section{Actividad 3. Proyección del video}

Se presenta un video cuya función es la de organizador anticipante de la información: El ojo y la visión (Serie Didavisión). El video muestra en primer término el papel que juega el sentido de la vista en la obtención de datos acerca del mundo. Luego los distintos sistemas de visión, desde el ser humano hasta los insectos. Se comparan las visiones frontales y laterales, se hace referencia a los ojos compuestos, la visión estereoscópica humana y se presenta un esquema del ojo y de la marcha de los rayos, indicando la presencia de conos y bastones en la retina y sus funciones. En el video se retoman los puntos principales al final, a la manera de resumen.

En tanto organizador anticipante, lo que se pretende con este video es activar conceptos inclusores que sirvan de anclaje a las nuevas ideas que se pretende que se construyan. En principio, se trata de fundamentar la importancia de la visión como puerta de ingreso a gran caudal de información. Este 
video muestra las relaciones entre lente, rayo e imagen diagramada en la retina, conceptos complejos que sólo son enunciados aquí. Además de anticipar temas, sirve como marco referencial, ya que aparecen, por ejemplo, esquemas representativos de marcha de rayos cuando se explica la formación de imágenes en la retina. Tal información puede llegar a ser recuperada por los alumnos cuando en actividades siguientes se les proponga que realicen esquemas descriptivos.

Si no se dispone del video mencionado se puede usar alguno de los que se presentan en las siguientes direcciones:

Sentido de la vista http://www.youtube.com/watch?v=bsURjCUTl30

La visión $\quad$ http://www.youtube.com/watch?v=mvBoWKe6QK0

El cuerpo humano: visión http://www.youtube.com/watch?v=iNL2xtB5c6A

Ojo humano http://www.youtube.com/watch?v=PZEsR2hq4Qk

\section{Actividad 4. ¿Sentido de visión o sentido común?}

Finalizada la proyección, se pregunta a los alumnos si agregarían algo nuevo a lo que ya se había escrito en el pizarrón (Actividad 2) y los aportes son incorporados a la lista. Se invita a apreciar los cambios post-video interrogando acerca de si las respuestas dadas en la actividad 2 son coherentes con la afirmación de la importancia de la visión para el ser humano y para el resto de los animales, o si solamente siguen ideas de sentido común.

Finalmente se indaga acerca de si modificarían sus respuestas para el caso de las personas no videntes. Una pregunta conducente a ello podría ser: ¿Cuáles de estas cosas una persona ciega podría hacer de otro modo?

Se subrayan en el pizarrón las funciones que una persona ciega debería suplir y se anota cómo creen que las puede compensar.

Lo que se pretende con la actividad post-video es que los alumnos puedan explicar con mayor profundidad y complejidad por qué es importante la visión. De esta manera pueden comparar sus respuestas y evidenciar en qué reside esa mayor profundidad y complejidad de sus explicaciones. Otro propósito es que puedan identificar las puertas de entrada de información alternativas para las personas ciegas, en cuanto a la utilización de otras funciones sensoriales. Esto último propende a que los alumnos se apropien de una concepción no discriminatoria, de respeto por las diferencias.

\section{Actividad 5. ¿Qué fue lo primero que hicimos al iniciar la clase?}

$\mathrm{Al}$ final de la clase 1 el docente retoma las cuestiones del inicio: "juego proyector - pantalla - foco", con preguntas de recuperación: ¿Qué fue lo primero que hicimos al iniciar la clase? ¿En qué condiciones de las experimentadas hubo imagen nítida? ¿Qué características tiene una imagen nítida? ¿Por qué tiene que estar la pantalla?

El docente señala que estas respuestas que se van produciendo tendrán cada vez más sentido a medida que avancen las actividades de la unidad.

Se procura que los alumnos identifiquen los elementos necesarios para la percepción de imágenes. Que analicen el fenómeno en función de describir las situaciones en las cuales se conformaron imágenes nítidas. Al mismo tiempo, se estimula a los alumnos a que propongan explicaciones a los diferentes "por qué" plantados, lo cual involucra la formulación de hipótesis provisorias, susceptibles de ser puestas a prueba a lo largo de la unidad. 


\section{Clase II. Enseñanza de los elementos constitutivos del proceso}

\section{Actividad 6. ¿Cómo viaja la luz de manera que podemos ver?}

El docente propone a los alumnos que describan el fenómeno por el cual pueden ver la lapicera con la cual escriben. Se parte de consensuar que, para ocurrir ese fenómeno, deben estar -como mínimo- la lapicera, el ojo del observador y una fuente de luz. Para ello el docente previamente dispara la pregunta: ¿Qué elementos participan necesariamente para poder ver la lapicera?

Para indagar qué ideas previas presentan en este sentido, les propone que se agrupen de a cuatro. Cada grupo dispone de un marcador, regla y un papel afiche donde ya previamente han sido dibujados la fuente, el ojo y la lapicera (ver figura).

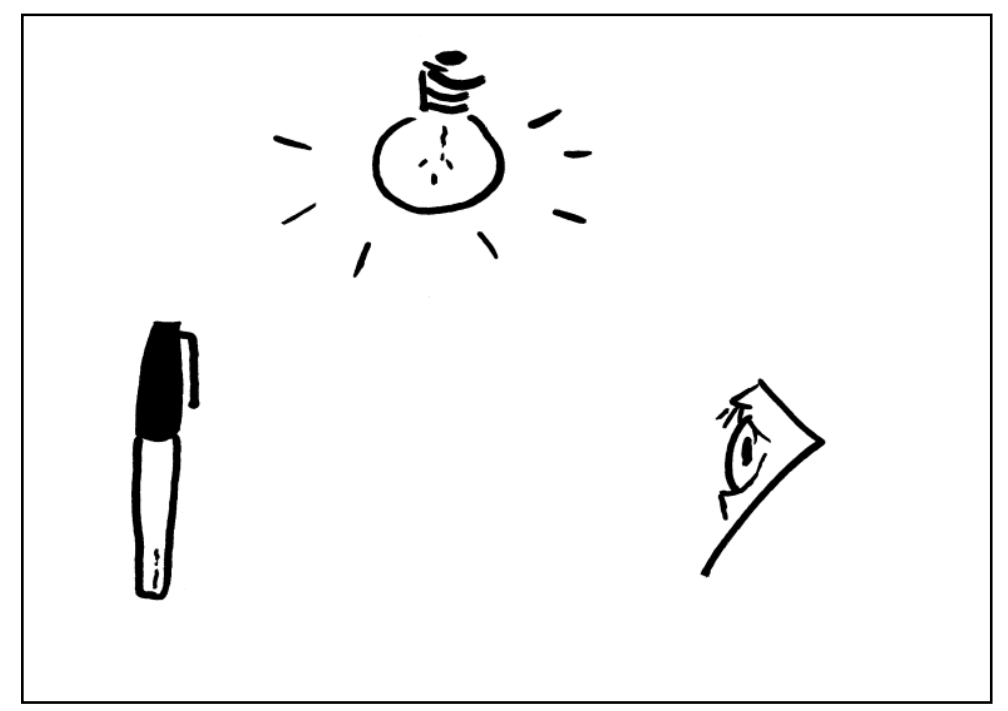

El docente pide que en el esquema dibujen con líneas, rayos o flechas, cómo creen que se produce la percepción de la lapicera.

A modo de orientación previa, el docente pauta que entre los integrantes del grupo acuerden qué representación les resulta más útil para la descripción. Además, les aclara que deben comentar a los demás integrantes del curso por qué eligieron dibujar el fenómeno de esa forma.

Las láminas se exponen todas juntas en el pizarrón, y los grupos por turno van explicitando oralmente sus ideas al respecto. Cuando hay grupos que presentan esquemas muy parecidos, el docente trata de consensuar con los alumnos sobre cuáles esquemas les parecen semejantes, señalándolos y agrupándolos.

Como se indicó más arriba, esta actividad pretende que los alumnos puedan dar cuenta de sus concepciones alternativas acerca del fenómeno en estudio. En ese sentido, varios trabajos de investigación (Osuna García y Martínez Torregrosa, 2001 y 2005) han detectado representaciones alternativas en los alumnos que se constituyen en verdaderos obstáculos a la hora de apropiarse de modelos científicamente correctos. Algunas de las explicaciones que han sido documentadas son: 
Vemos porque: la miramos, el ojo envía la mirada hacia la lapicera, de ella sale la imagen que llega hasta el ojo, de ella sale una imagen y el ojo envía la mirada, la luz que sale de ella llega hasta el ojo. A partir de un primer paso que pretende que los alumnos identifiquen los elementos que intervienen en el fenómeno, a continuación se busca que traten de describirlo utilizando representaciones gráficas y verbales. El eje que atraviesa toda la unidad didáctica pasa por estimular a los alumnos a la producción de representaciones sucesivamente más útiles a la hora de describir (y más adelante explicar) los fenómenos de percepción de los objetos. En esta actividad en particular también se busca detectar en el alumnado aquellas ideas previas que puedan constituirse en obstáculos para el desarrollo de representaciones adecuadas.

\section{Actividad 7. ¿Qué hacemos entonces?}

Se pide a los estudiantes que traten de hallar las debilidades y las fortalezas de los modelos propuestos, a partir de preguntas tales como: ¿Por qué les parece que este o aquél esquema responde más satisfactoriamente al hecho de poder ver la lapicera?

No obstante, no se descalifica ninguna producción. Las actividades que siguen tienden a la superación de los obstáculos detectados.

Uno de los propósitos de esta actividad es lograr en los alumnos una primera aproximación a lo que significa encontrar fortalezas y debilidades de las representaciones expuestas, a partir de favorecer un debate que implique a los grupos fundamentar sus posturas. En ese sentido, se procura que los alumnos construyan argumentos en pos de defender las representaciones más potentes en comparación con otras. También se tiende a acercarlos a la idea de que no hay representaciones $o$ modelos "correctos", sino más bien al carácter perfectible y provisional de los mismos.

\section{Actividad 8. Observación y registro}

El docente menciona: “Tal vez deberíamos observar otras experiencias y tener un mayor caudal de información. Pero para ello, no sólo tenemos que mirar así nomás otros casos, otros ejemplos". Para empezar, se propone a los alumnos que en el transcurso de esta semana y las subsiguientes, observen fenómenos relacionados con la luz y la visión, tan simples como la sombra de un objeto, el paso de luz por una ventana, las distorsiones en los espejos antiguos, vasos con líquidos o copas.

Se pide recolectar la mayor información y con la mayor precisión posible. Para ello solicita que escriban sus observaciones o experiencias en hojas aparte de la carpeta, siempre acompañadas de un dibujo, diagrama o bosquejo.

Cuando el docente enuncia estas tareas a realizar, explicita a los alumnos que la observación y registro de tales fenómenos ayudará a tener elementos que contribuirán a construir una manera de describirlos y explicarlos.

La intención es que los alumnos describan fenómenos lumínicos de la vida cotidiana, como una manera de ejercitar la atención en pos de relacionarlos con los contenidos abordados y por abordar. De esta manera, además, se les otorga significatividad a los mismos. 


\section{Clase III. Experiencias discrepantes tendientes a la superación del obstáculo "ojo activo"}

Algunas de las respuestas dadas en la actividad anterior corresponden a una concepción de "ojo activo", también llamada de extramisión. En ella, se sostiene que "algo" que sale del ojo va al encuentro del objeto a ser observado, es decir, una concepción más bien "táctil" del proceso de visión. O bien, que ese "algo" que sale del ojo se encuentra a mitad de camino con "algo" que sale del objeto. En pos de contraponer evidencia a tal concepción, es que se recurre a las siguientes actividades.

\section{Actividad 9. Ejercicio de imaginación}

El docente propone a los alumnos la siguiente experiencia: Piensen que están en el interior de una habitación completamente a oscuras, sin ninguna rendija que permita que se filtre luz desde el exterior ¿verían o no la habitación? ¿por qué?

Es muy probable que la respuesta de los alumnos y las alumnas sea: "No vemos porque no hay luz", con lo cual no podemos garantizar que hayan descartado la idea del "ojo activo" puesto que le estarían otorgando a la luz un carácter "contextual", de condición necesaria pero no suficiente. Nuestra intención es que los alumnos reconozcan que es necesaria la luz de una fuente. En las actividades sucesivas se considerará siempre ese elemento.

En esta instancia se presentan ejemplos acerca del concepto de fuente primaria y se acuerda una definición posible.

Se espera remitir a los alumnos a experiencias vividas a partir de las cuales poder identificar qué elementos están presentes en dicha situación y cuáles no. En ese sentido, que puedan explicar por qué no ven. Una vez que reconocen el carácter necesario de la luz (aunque sea, como queda señalado, en su variante "contextual") se hace referencia a las fuentes primarias de luz.

\section{Actividad 10. ¿Podemos ver la luz mientras viaja?}

A partir de formular a los alumnos la pregunta que da título a la actividad, se propone la siguiente experiencia: se les presenta una caja cerrada de interior negro mate y que presenta dos orificios en sus lados menores, en la misma posición relativa. En uno de ellos se coloca apoyada una linterna encendida, pudiéndose apreciar que la luz sale por el otro extremo al interponer, por ejemplo, la mano. Lateralmente, la caja presenta una abertura (que puede ser cubierta o descubierta a voluntad), a través de la cual un observador puede mirar el interior de la caja.

El docente muestra la entrada y la salida de la luz y pide a los alumnos que predigan qué van a observar si miran por el orificio (ver figura).

Algunas respuestas que hallamos fueron: "vamos a ver la caja iluminada por dentro" o bien "vamos a ver el rayo de luz". 


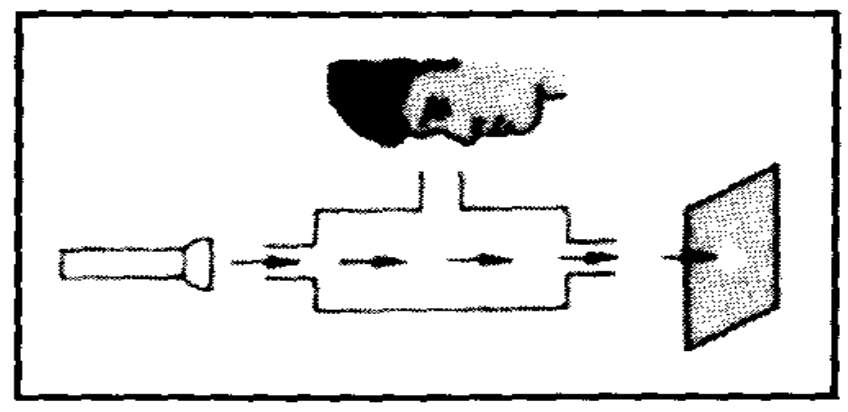

Luego, se deja que los alumnos practiquen la experiencia y puedan evidenciar que "no ven nada". Esta experiencia les puede mostrar que, si bien ahora tenemos la luz y tenemos el ojo, igual no vemos. ¿Qué hace falta?

Según Friedl (2000), esta experiencia demuestra que la luz es invisible cuando se propaga. La fuente de luz (la luz de la linterna) y el objeto en el cual se refleja son visibles (mantenga su mano en el rayo de luz); pero la luz es invisible cuando pasa a unos centímetros del ojo".

En este punto, el docente pide a los alumnos que recuerden la situación en la que se estaba apuntando la luz del proyector hacia la apertura de la ventana, o cuando se lo hacía sobre la pantalla. También se puede comentar a los alumnos y alumnas que: "Tendremos un buen ejemplo de luz invisible si miramos hacia el cielo en una noche clara. La propagación de la luz del sol $[\ldots]$ no se puede ver; recién se puede ver la luz cuando choca contra algo (como la luna o un planeta)".

A partir del ejercicio anterior se pretende que los estudiantes: a) puedan transferir las variables en juego (que han sido ya identificadas en actividades anteriores) al nuevo contexto; b) puedan inferir a partir de la interacción de dichas variables en esta situación nueva y predecir qué es lo que pasará al acercar el ojo a la abertura, c) que formulen hipótesis que permitan explicar el fenómeno. Además de que pueden comprobar que la luz "no se ve", esta instancia suma evidencia para la superación de la concepción de "ojo activo": en la actividad anterior, donde imaginan la habitación completamente a oscuras, los alumnos pueden concluir que no se ve por la ausencia de luz (condición contextual) sin que necesariamente hayan superado la extramisión. En esta actividad está presente el ojo y también la luz, y sin embargo siguen sin ver. Se trata ésta, por lo tanto, de lo que se suele denominar una "experiencia discrepante".

\section{Actividad 11. La trayectoria de la luz. Fuentes primarias y secundarias}

El docente entrega una lámina con un diagrama como el de la figura.

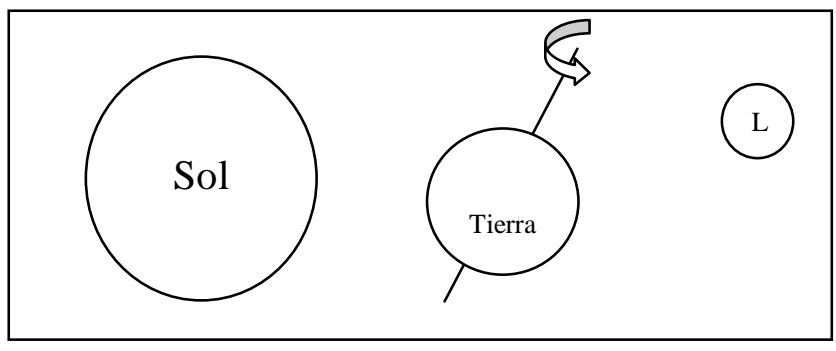

Se pide a los estudiantes que dibujen en él una posible trayectoria de la luz que permita que las personas ubicadas en la Tierra puedan ver la Luna. Luego se presentan ejemplos acerca del concepto de fuente secundaria. Se acuerda una definición posible y se la compara con lo que se había convenido en llamar anteriormente fuente primaria.

En el mismo sentido que experiencias anteriores, lo que se propone aquí es el afianzamiento paulatino de esquemas de representación de la luz como "rayo". Si bien consideramos poco probable que a esta altura los alumnos puedan modelizar idealmente la marcha de rayos (en el sentido de la Óptica), las 
representaciones que pueden alcanzar se constituyen en descriptores adecuados, que dejan la puerta abierta a mejores conceptualizaciones.

\section{Clase IV. Aplicación de los nuevos marcos conceptuales a otras situaciones}

\section{Actividad 12. La luz mientras viaja no se ve, ¿o sí?}

Esta actividad se inicia con la pregunta del docente: Supongamos que es de día y se filtran unos rayos de luz por la ventana en una habitación recién barrida ¿se verán los rayos de luz?

A continuación, el docente sacude el borrador con tiza en un sector del aula y pregunta a los alumnos y alumnas si acaso no parece que pueden verse los rayos de luz que se filtran por la ventana. A continuación, formula las siguientes preguntas:

¿Por qué creen que pueden verlos? ¿No se contradice esto con lo que comprobamos con la experiencia de la caja pintada de negro?

El docente pide que los estudiantes pongan por escrito las hipótesis que consideren plausibles para dar cuenta del fenómeno.

Esta actividad parte de ofrecer una posible respuesta anticipándose a una eventual pregunta de los alumnos referida a que "en ciertas circunstancias" la luz se ve. Los alumnos pueden hacer hipótesis acerca de las condiciones que hacen que la luz se vea (relacionándolo con los conceptos construidos hasta aquí) y tratar de lograr explicaciones en base a los esquemas que han venido mejorando paulatinamente a lo largo de la unidad.

\section{Clase V. Detección de modelos erróneos subyacentes en diferentes contextos}

En estas dos últimas actividades se pide a los alumnos que identifiquen, en diferentes contextos, qué elementos corresponden a la concepción de ojo activo (es decir, a la concepción que se ha tratado de superar).

\section{Actividad 13. Superman, el "extramisionista"}

El docente entrega a cada grupo una hoja con viñetas del cómic "Superman" en las que se lo ve haciendo uso de su particular visión, que emite rayos X. La consigna es que identifiquen qué cuestiones de dichas viñetas no concuerdan con el modelo que han venido construyendo y que expliquen por qué.

\section{Actividad 14. ¿Lenguaje científico o poético?}

Se entrega a los alumnos y alumnas un texto para que lean individualmente. Deben determinar qué frases del mismo, que si bien son agradables para nuestros oídos o son muy comunes en el hablar, no están de acuerdo con el esquema de visión propuesto. Deben comentar qué aspectos del breve relato les dan indicios de ello.

Texto para analizar

“En ese momento, la profesora me alcanzó con su mirada. Esta mirada yo ya la conocía: recorrió centímetro a centímetro cada lugar de mi banco, mi mesa, mi ropa, tratando de encontrar el machete que -ella suponía- estaría en algún lugar. No habiendo obtenido éxito, los ojos fulminantes cayeron sobre el pobre de Brian, quien nunca en su vida había 
intentado copiarse. Como si hubiera sido afectado de repente por esa fuerte mirada, la mano de Brian golpeó sin querer la regla, que cayó al piso, mostrando en todo su esplendor escrito, prolijamente en su dorso, el teorema de Pitágoras".

\section{Algunos resultados que surgieron de la implementación de la Unidad Didáctica}

\section{Elicitación de las concepciones alternativas}

Se muestran a continuación los esquemas realizados por los grupos de alumnos y alumnas, con el texto explicativo que produjeron.

\section{Grupo 1}

"Nuestra opinión es que si no hay luz por más que tengamos los ojos abiertos no vemos la lapicera. En cambio si tenemos luz vemos la lapicera"

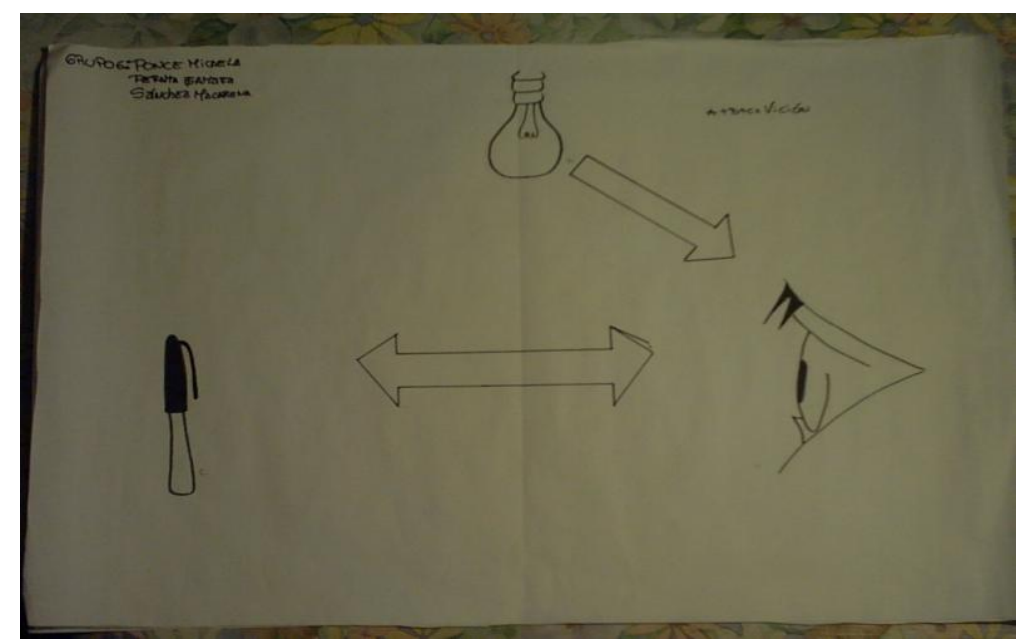

\section{Grupo 2}

"La luz apunta a todos lados, va al ojo y a la lapicera. Con la luz apuntando a la lapicera la visión se trasmite al ojo. La visión transpasa el cristalino produciendo la visión hacia la lapicera."

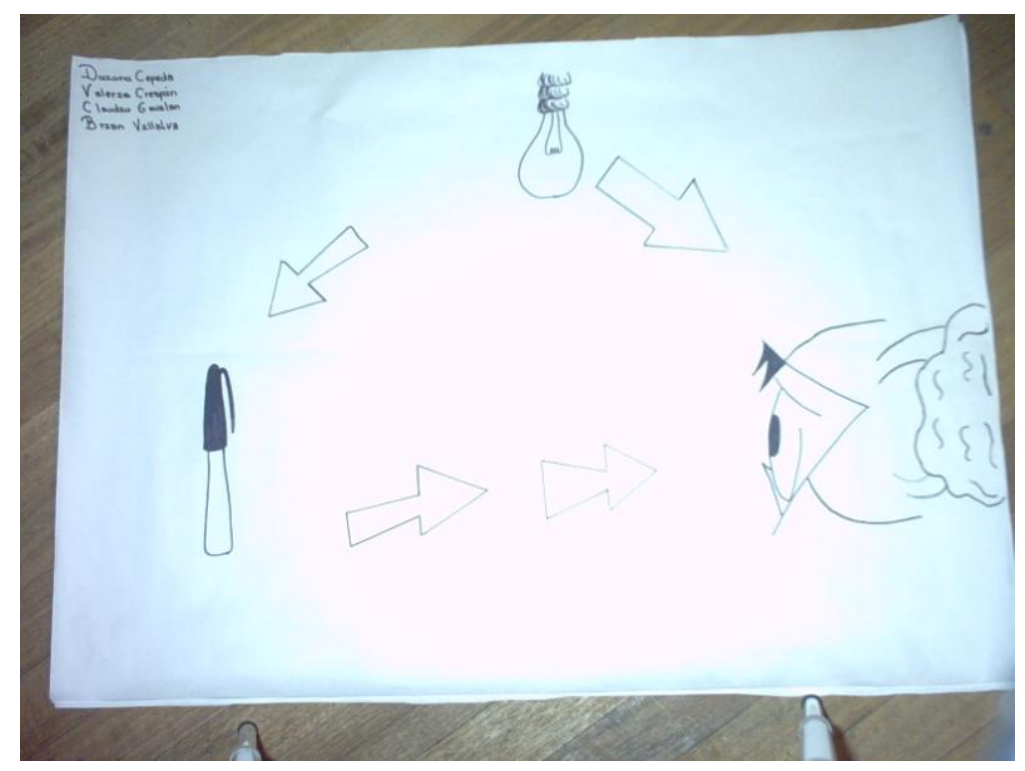


Bio-grafia: Escritos sobre la Biologia y su Enseñanza Vol 3 No5 ISSN 2027 -1034. Segundo semestre de 2010, Bogotà, Colombia, pp 192- 206

\section{Grupo 3}

"La luz refleja al ojo y el ojo puede captar la visión de la lapicera."

\section{Grupo 4}

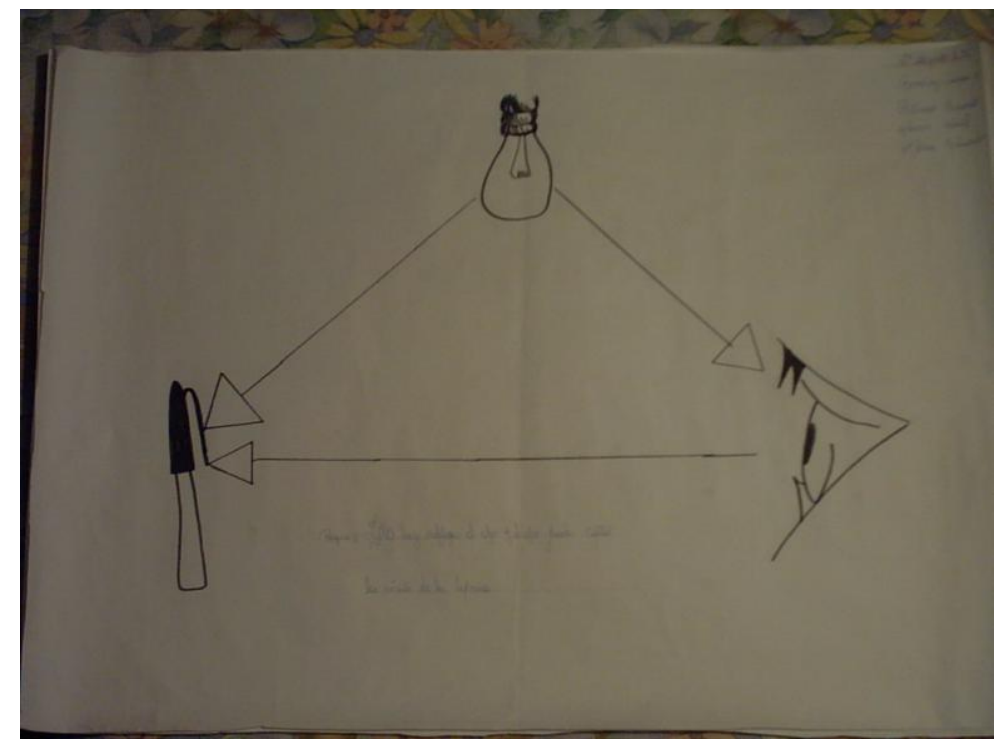

“Pensamos que la luz refleja en la lapicera. Y al reflejar la luz en la lapicera refleja así a los ojos".

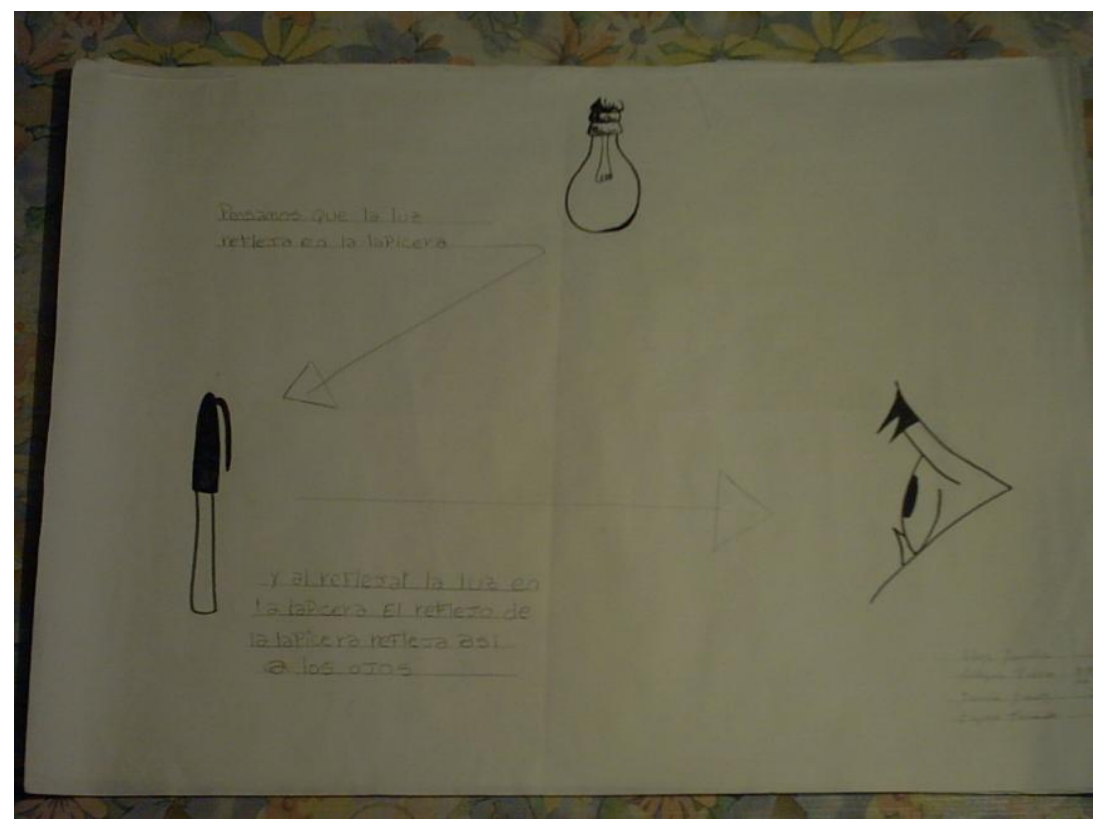

\section{Grupo 5}

"La luz llega al ojo para poder ver la lapicera y el ojo al ver la luz puede ver la lapicera. O si no la luz puede llegar a la lapicera y ahí le da el reflejo para que el ojo pueda ver la lapicera 
Bio-grafia: Escritos sobre la Biologia y su Enseñanza Vol 3 No5 ISSN 2027 -1034. Segundo semestre de 2010, Bogotà, Colombia, pp 192- 206

\section{Grupo 6}

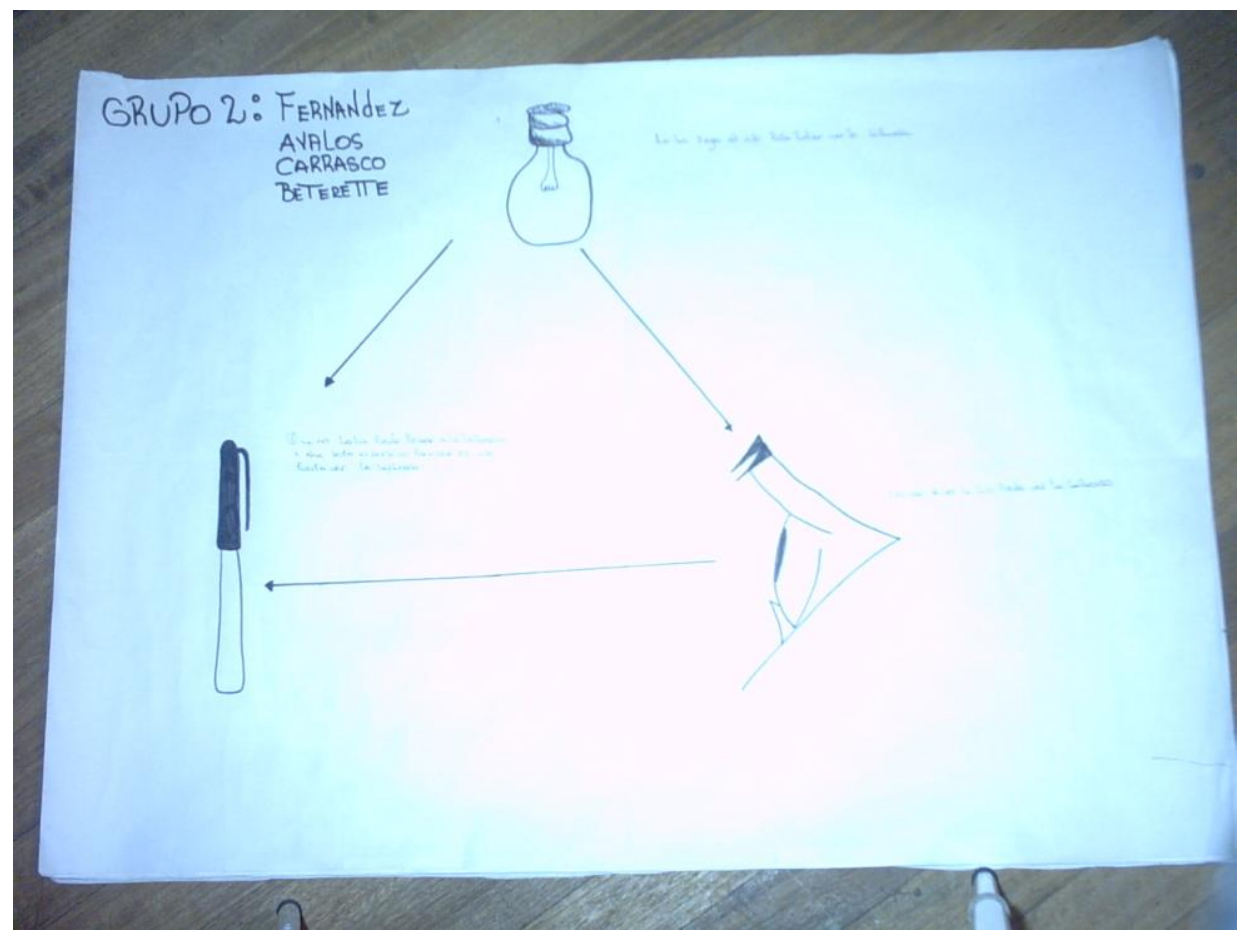

"La luz refleja el objeto y hace posible que se pueda ver la lapicera con los ojos, que de la retina manda energía eléctrica al cerebro."

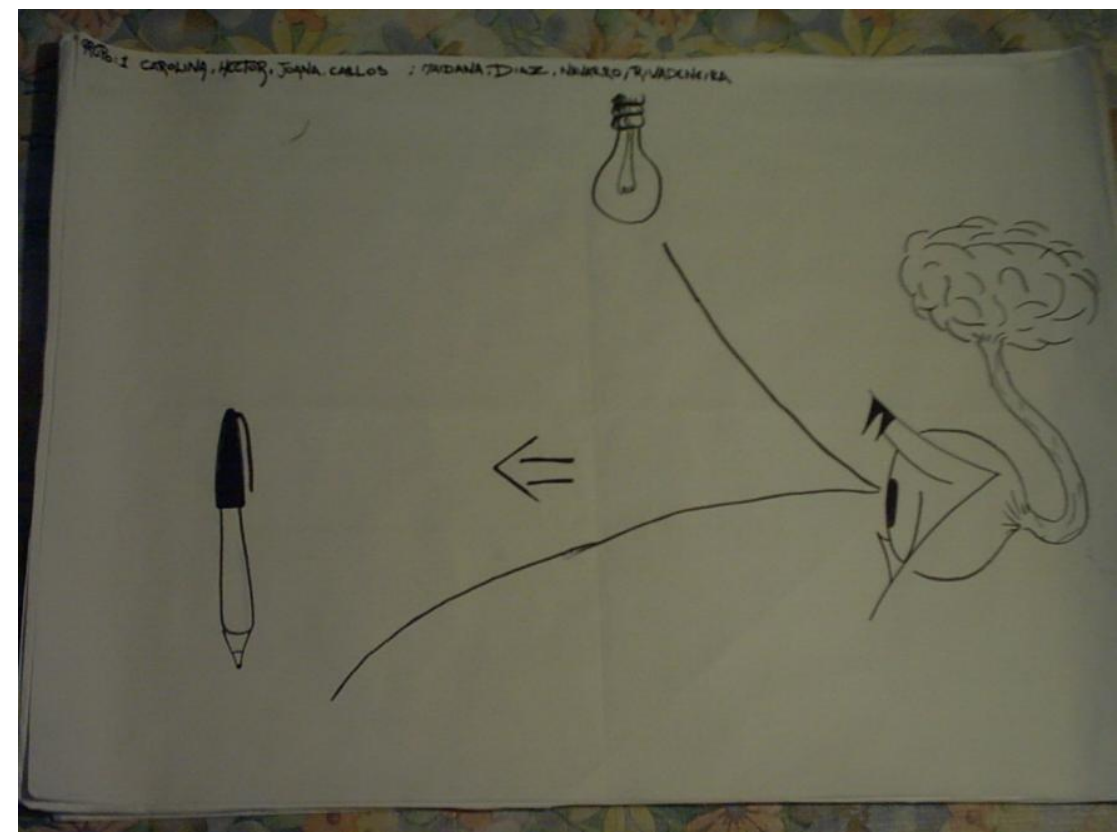




\section{Comentarios sobre las exposiciones}

En lo estrictamente relacionado con la construcción de explicaciones por parte de los alumnos y alumnas, no deja de resultar sorprendente cómo las tipologías referidas a preconcepciones que refiere la bibliografía se encuentran tan significativamente representadas en la población de alumnos y alumnas con los que trabajamos. Como era de esperar, se encontraron algunas cuestiones polisémicas respecto de términos (y grafismos) que fue conveniente acordar.

Con todo, los grupos no tuvieron dificultad en explicar verbalmente qué era lo que habían querido representar en los dibujos (salvo en casos particulares donde lo que decían no coincidía con lo que se expresaba gráficamente).

Sin embargo, la dificultad se hizo evidente llegada la instancia de "ponerse en lugar del otro", es decir, tratar de explicar qué era lo que habían intentado decir los compañeros de otro grupo. En ese sentido, lo que se evidenció fue más bien una tendencia a decir por qué lo del otro grupo estaba mal. En esos casos, se trató de reencauzar hacia la idea original de la planificación, que es ayudarlos a encontrar cuáles de las representaciones eran más potentes a la hora de explicar el fenómeno, sin que por ello se descalifique ninguna producción. Además, como se ha señalado anteriormente, se hizo necesario asumir una suerte de "acuerdos de representación" a la hora de interpretar las producciones: esto es, que dentro de un mismo grupo, la repetición de una misma simbología responda al mismo concepto.

Algo interesante que no conviene dejar de señalar es que muchos alumnos, cuando plantean su supuesto "extramisionismo", desde lo que verbalizan se podría inferir que se trataría no tanto de que "algo sale del ojo" (Vg. luz) sino como una forma de subrayar o destacar de alguna manera la necesaria actividad del ojo desde su función, llamando a ese "protagonismo" visión.

\section{Instancias de evaluación: en la búsqueda de indicios de cambio representacional}

Como corolario de todas las instancias tendientes a desestabilizar los obstáculos y a presentar la plausibilidad del modelo científico, las actividades 13 (Superman, el "extramisionista") y 14 (¿Lenguaje científico o poético?) tuvieron como objetivo indagar si las y los estudiantes podían detectar cuáles eran las ideas no compatibles con el modelo científico que estaban presentes en la historieta y en el relato. En el caso de Superman, la mayoría interpretó rápidamente la consigna ("Nosotros vimos que la luz no sale de los ojos, sino que llega a los ojos"). Unos pocos se limitaron a decir que está mal porque "no tenemos superpoderes" o bien "la visión no larga calor". En cuanto al relato, en general, pudieron señalar aquellas cosas que les parecieron que no se correspondían ("me alcanzó con su mirada", "los ojos fulminantes cayeron...") pero no todos alcanzaron a poner en palabras por qué esas expresiones no se compatibilizan con el modelo construido.

Lo señalado anteriormente muestra, una vez más, que las ideas previas de las y los estudiantes se constituyen en verdaderos obstáculos para la consecución de genuinos aprendizajes científicos; que sus ideas alternativas necesitan ser explicitadas y que es tarea de los docentes hacer que esto se logre para que los propios alumnos/as tomen consciencia de ellas si se espera -al menos- una vigilancia epistemológica, como menciona Astolfi.

Un enfoque como el que se propone aquí requiere propiciar un ambiente de trabajo donde el error no sea castigado, donde se enseñe a las y los estudiantes a explicitar sus ideas y a 
avanzar en el camino de la construcción de nuevas explicaciones a partir de los modelos científicos, de manera de convertir esta transición en un progresivo proceso metarreflexivo.

\section{Consideraciones finales}

En el momento de pensar esta planificación inicialmente se intentó abordar una cantidad mucho mayor de contenidos conceptuales. Sin embargo, la experiencia docente y de formadores de formadores del equipo de trabajo nos llevó rápidamente a ver que, a pesar de los numerosos esfuerzos de los docentes por "dictar" más, los alumnos no logran comprender los conceptos y procesos. Esto es bastante fácil de ver si en algún momento de la clase interrogamos de manera genuina a los estudiantes. Es decir, no simulamos un diálogo sino que verdaderamente los ponemos en situación de tener que explicar algún. Un lector desprevenido podrá pensar que hemos propuesto 14 actividades para abarcar muy pocos temas; sin embargo, nuestra intención no ha sido "dar" el tema, sino proponer actividades para que los estudiantes trabajen y pongan en juego sus habilidades cognitivolingüísticas en la resolución de problemas (Valeiras y Meinardi, 2007).

Nuestra reflexión final es que es importante que el docente se detenga a pensar acerca de las finalidades de la educación que pone en juego al planificar la enseñanza; esto tal vez lo lleve -al menos eso esperamos- a reflexionar profundamente sobre la importancia de la comprensión de los fenómenos por sobre el conocimiento meramente declarativo que suele producirse en la enseñanza tradicional.

\section{Bibliografía}

Astolfi, J-P. (2001). Conceptos clave en la didáctica de las disciplinas. Sevilla: Dìada Editora.

Friedl, A. (2000). Enseñar ciencias a los niños. Barcelona: Gedisa.

Meinardi, E. (2007). Reflexiones sobre la formación inicial de los profesores de Biología. Revista de Educación en Biología 10(2), 48-54.

Meinardi, E. (coord.), González Galli, L., Revel Chion, A. y Plaza, M.V. (2010). Educar en ciencias. Buenos Aires: Paidós.

Osuna GARCÍA, L. y Martínez-Torregrosa, J. (2001). La elaboración de una unidad didáctica sobre "la luz y la visión": análisis de las barreras históricas y su relevancia en la enseñanza. Actes V Jornades de la Curie.

Osuna García, L. y Martínez-Torregrosa, J. (2005). La enseñanza de la luz y la visión con una estructura problematizada: propuesta de secuencia y puesta a prueba de su validez. Enseñanza de las Ciencias, Número Extra.

Valeiras, N. y Meinardi, E. (2007). La enseñanza de la biología, las reformas educativas y la realidad del profesorado en Argentina. Alambique, 51, 58-65. 